\title{
Current Status of Adverse Drug Reaction Reporting by the Physicians in A Medical College Hospital
}

Maliha Ata ${ }^{1 *}$

Rozina Hoque ${ }^{1}$

Asma Mostafa ${ }^{2}$

Md. Rakibul I. Shakil

Rajat Sanker Roy Biswas ${ }^{3}$

Salma Akhter ${ }^{4}$

Shamsunnahar B. Mannan ${ }^{5}$

'Department of Pharmacology \& Therapeutic Chattogram Maa-O-Shishu Hosital Medical College Chattogram, Bangladesh.

${ }^{2}$ Department of Anatomy

Chattogram Maa-O-Shishu Hosital Medical College

Chattogram, Bangladesh.

${ }^{3}$ Department of Medicine

Chattogram Maa-O-Shishu Hosital Medical College

Chattogram, Bangladesh.

${ }^{4}$ Department of Gynaecology \& Obstetrics Chattogram Maa-O-Shishu Hosital Medical College Chattogram, Bangladesh.

${ }^{5}$ Department of Skin \& VD Chattogram Maa-O-Shishu Hosital Medical College Chattogram, Bangladesh.

\footnotetext{
*Correspondence to:

Dr. Maliha Ata

Associate Professor

Department of Pharmacology \& Therapeutics Chattogram Maa-O-Shishu Hospital Medical College Chattogram, Bangladesh.

Mobile : +8801910837966

Email :dr.maliha59@gmail.com
}

Date of Submission : 29.03 .2021

Date of Acceptance ： 20.06 .2021

\begin{abstract}
Background: In order to improve the spontaneous Adverse Drug Reaction (ADR) reporting practice by the physicians, there is an obligatory need to investigate the current situation of $A D R$ reporting by them. The study was conducted to observe the $A D R$ reporting pattern among physicians in a tertiary medical college hospital.

Materials and methods: This was a descriptive cross sectional study carried out in a tertiary medical college hospital during the study period of March 2020 to October 2020. Data were collected from 100 physicians working on different departments using self designed pretested questionnaire by convenient sampling technique.

Results: Among the 100 respondents 70 provided response to questionnaire giving a response rate $70 \%$. Most of the respondents (61.43\%) had adequate knowledge on $A D R$ reporting. A good number of respondents showed positive attitude but there is no practice of $A D R$ reporting though most of the respondents (84.3\%) had experienced it in last 1 year. Most of the respondents experienced ADR with antibiotic (81.35\%), NSAIDs (33.89\%) \& anticonvulsants (15.25\%) and maximum (44.06\%) experienced ADR was with skin, $30.50 \%$ with GIT and $23.03 \%$ with respiratory system involvement. The cause of under reporting was mainly due to inaccessible ADR form, busy schedule, unaware of how and whom to report and lack of motivation to report. The respondents would be encouraged to report ADR if they were provided with simple \& available reporting form, regular guideline \& bulletin.
\end{abstract}

Conclusion: There is an urgent need for educational training \& seminar regarding our national online reporting system to emphasizing ADR reporting.

Key words: Adverse drug reaction; Pharmacovigilance; Spontaneous reporting.

\section{INTRODUCTION}

World Health Organization (WHO) defines an Adverse Drug Reaction (ADR) as 'any response to a drug that is noxious and unintended, and that occurs at doses used in humans for prophylaxis, diagnosis, or therapy, excluding failure to accomplish the intended purpose' ${ }^{1}$. ADR represents a major health problem ${ }^{2}$. One of the accepted reason for worldwide mortality and morbidity is ADR which is also a significant economic burden on health care resource ${ }^{2,3}$. Each year the rates of ADR related deaths ranged from $0.08 / 100,000$ to $0.12 / 100,000$ and the rate increases significantly over time at a rate of 0.0058 per year ${ }^{4}$. Approximately $2.9 \%-5 \%$ of all hospital admission is due to ADR and 35\% ADR are observed during their hospital days ${ }^{5}$. So it is essential to monitor and detect ADRs to minimize or prevent harmful effects of drugs before they are clinically manifested, and to acquire much more knowledge to ensure safe usage of drugs ${ }^{6}$. 
Safety and efficacy are the two major concerns about a drug. Efficacy of a drug can be measured easily but the safety cannot be quantified, it should be detected, assessed and prevented. This gave birth to the branch of Pharmacovigilance (PV). By definition, pharmacovigilance is, "The science and activities relating to the detection, assessment, understanding and prevention of adverse effects or any other drug-related problems"7. Concept of Pharmcovigilance started after the thalidomide disaster in the mid-20th century ${ }^{8}$. Among the various methods, spontaneous reporting has contributed significantly to successful pharmacovigilance.

Physicians can play a very crucial role in detection of serious and unusual ADR that were previously undetectable by spontaneous reporting of ADR around the world. It is a professional obligation of physicians to report ADR, as this effective reporting system is directly related to patient's safety 9 . Inspite of professional obligation and patient's safety issue, under-reporting is the major pitfall of successful spontaneous reporting system ${ }^{10-11}$. Approximately only $6-10 \%$ of all ADRs are reported and underreporting is estimated higher than 90$95 \%{ }^{12-13}$. In Bangladesh, Pharmacovigilance was introduced and practiced under supervision of WHO-UMC (WHOUppsala monitoring committee). Adverse Drug Reaction Monitoring Cell (ADRMC) was established under Directorate General of Drug Administration (DGDA) in $1996^{14}$. The most crucial thing for any Pharmacovigilance system is the prompt reporting of ADR. In our country this reporting can be done by online submission to the ADRM cell in DGDA.

All private and government institutional Health Care Professionals (HCP) are encouraged to submit ADR report spontaneously. Still many physicians in our country are unaware of the existing function and purpose of national ADR reporting procedure. Due to lack of this awareness physicians are staying behind the pioneer role in saving lives.

ADR reporting is a very simple method but this most important information is not known to many of the physicians in our country. Unfortunately the physicians in Bangladesh do not submit ADR report in a regular basis. Our physicians can play a vital role in ADR reporting and can improve our pharmacovigilance system, but they should have proper Knowledge, Attitude and Practice (KAP) regarding this valuable practice.

Taking Consideration to all these phenomena our study will aim of assessing physician's KAP of ADR reporting. This study will also attempt to find out their opinion about barrier to such procedure, detect the factor which encourages them to report in a tertiary medical college hospital, Chattogram, Bangladesh.

\section{MATERIALS AND METHODS}

This was a descriptive cross sectional questionnaire based study carried out in a tertiary medical college hospital during the period of March 2020 to October 2020. The study was conducted using self designed pre tested questionnaire to obtain information on knowledge, attitude and practice of physicians towards adverse drug reaction reporting along with their experience on adverse drug reactions and reporting, their opinion on barriers of reporting, preferred method of reporting, and factors those encourage on reporting. Data were collected from 100 physicians working in the different department by convenient sampling technique. The study was approved by Chattogram Maa-O-Shishu Hospital Medical College (CMOSHMC) Ethical Committee. Data was analyzed using SPSS software (Version 18).

\section{Knowledge Scoring Regarding ADR \& It's Reporting System} An effort was made to find out the overall knowledge of the respondents. There were 16 questions related to knowledge and each right answer was given the score " 1 " and each wrong answer \& unknown knowledge was given the score "0". On the basis of individual score respondent knowledge was categorized as adequate knowledge ( $>66 \%$ ) moderate knowledge (66-34\%) and poor knowledge $(<34 \%)$.

\section{RESULTS}

In total 100 questionnaire were distributed and the response rate was $70 \%$. 31.4\% physicians had experience less than 1 year, $30 \%$ physicians had experience for $1-5$ years and $14.3 \% \%$ physicians had experience for 6-10 years, $7.1 \%$ physicians experience for $11-15$ years, $7.1 \%$ had experience for $16-20$ years and $10 \%$ had experience for more than 20 years of their professional life. Among them $61.4 \%$ had MBBS degree and $38.6 \%$ completed their post graduate degree (Table 1 ).

Table I : Demographic profile of the physicians

\begin{tabular}{lr} 
Variables & Value \\
Median Age & 32 years \\
Total Physicians & 70 \\
Degree & \\
MBBS & $61.4 \%(43)$ \\
Post graduate & $38.6 \%(27)$ \\
Experience & \\
$<1$ year & $31.4 \%(22)$ \\
$1-5$ years & $30 \%(21)$ \\
$6-10$ years & $14.3 \%(10)$ \\
$11-15$ years & $7.1 \%(5)$ \\
$16-20$ Years & $7.1 \%(5)$ \\
$>20$ years & $10 \%(7)$ \\
\hline
\end{tabular}

There were 16 questions for assessing knowledge regarding ADR reporting. $71.4 \%$ physicians awarded the term pharmacovigilance, $74.5 \%$ physicians knew that ADR reporting is the part of pharmacovigilance and $90 \%$ physicians agreed that spontaneous reporting is the most common \& easiest way of ADR reporting. $82.9 \%$ physicians admitted that only physicians are not responsible for ADR reporting, it's the duty of all health care professionals (HCP). Only $12.9 \%$ physicians 
thought that it is not necessary to be confirmed that an ADR is related to a particular drug before reporting and only $45.7 \%$ physicians knew that they should report even if in doubt of a particular drug. Other positive knowledges are summarized in Table II.

In this study $61.43 \%$ physicians had adequate knowledge, $37.14 \%$ physicians had moderate knowledge and only $1.43 \%$ physicians had poor knowledge.

Table II : Evaluation of knowledge of physicians regarding ADR reporting

\begin{tabular}{|c|c|c|c|c|}
\hline $\begin{array}{l}\text { Serial } \\
\text { No }\end{array}$ & Knowledge & $\begin{array}{r}\text { Physicians \% } \\
\text { (Correct } \\
\text { knowledge) (n) }\end{array}$ & $\begin{array}{r}\text { Physicians \% } \\
\text { (Incorrect } \\
\text { knowledge) (n) }\end{array}$ & $\begin{array}{l}\text { Physicians \% } \\
\text { (Don't know } \\
\text { the answer) (n) }\end{array}$ \\
\hline 1. & Aware of term Pharmacovigilance & $71.4 \%(50)$ & $24.5 \%(17)$ & $4.3 \%(03)$ \\
\hline 2. & ADR reporting is the part of Pharmacovigilance. & $74.3 \%(52)$ & $5.7 \%(04)$ & $20 \%(14)$ \\
\hline 3. & $\begin{array}{l}\text { Spontaneous reporting is the most common and easiest way of } \\
\text { ADR reporting. }\end{array}$ & $90 \%(63)$ & $8.6 \%(06)$ & $1.4 \%(01)$ \\
\hline 4. & Only Physicians can report ADR & $82.9 \%(58)$ & $15.7 \%(11)$ & $1.4 \%(01)$ \\
\hline 5. & ADR reporting should be done only in case of allopathic medicine & $84.3 \%(59)$ & $11.4 \%(08)$ & $4.3 \%(03)$ \\
\hline 6. & International centre for monitoring is located in Sweden. & $47.1 \%(33)$ & $10 \%(07)$ & $42.9 \%(30)$ \\
\hline 7. & $\begin{array}{l}\text { Are you aware of the existence of the regulatory body that regulates ADR } \\
\text { reporting in Bangladesh }\end{array}$ & $58.6 \%(41)$ & $37.1 \%(26)$ & $4.3 \%(03)$ \\
\hline 8 . & $\begin{array}{l}\text { It is necessary to be confirmed that an ADR is related to a particular } \\
\text { drug before reporting }\end{array}$ & $12.9 \%(9)$ & $80 \%(56)$ & $7.1 \%(05)$ \\
\hline 9. & $\begin{array}{l}\text { You should not report if you are in doubt that this reaction is due to a } \\
\text { particular drug }\end{array}$ & $45.7 \%(32)$ & $52.9 \%(37)$ & $1.4 \%(01)$ \\
\hline 10 & ADRs should be reported only when they are serious \& life threatening & $82.9 \%(58)$ & $15.7 \%(11)$ & $1.4 \%(01)$ \\
\hline 11. & You should report ADR directly to WHO ADR monitoring cell & $25.7 \%(18)$ & $51.4 \%(36)$ & $22.9 \%(16)$ \\
\hline 12. & A good number of ADRs can be prevented if appropriate measures are taken & $91.4 \%(64)$ & $8.6 \%(06)$ & $00 \%(00)$ \\
\hline 13 & ADRs are one of the major cause of death in the world & $48.6 \%(34)$ & $27.1 \%(19)$ & $24.3 \%(17)$ \\
\hline 14. & OTC medications don't cause any ADR & $78.6 \%(55)$ & $17.1 \%(12)$ & $2.9 \%(02)$ \\
\hline 15. & Do you believe all the drugs available in the market are safe? & $90 \%(63)$ & $8.6 \%(06)$ & $1.4 \%(01)$ \\
\hline 16. & $\begin{array}{l}\text { Hartwig scale is used to establish the severity of ADRs \& Naranjo scale is } \\
\text { used for causality assessment }\end{array}$ & $30 \%(21)$ & $10 \%(07)$ & $60 \%(42)$ \\
\hline
\end{tabular}

$\mathrm{n}=70$

The majority of physicians (90\%) thought that ADR reporting could contributes to drug as well as patient safety and $80 \%$ believes that it's is a professional obligation respectively. 71.4\% physicians felt that ADR reporting is not a time consuming activity. $90 \%$ physicians did not consider that it would waste their time. It has to be mentioned that only $8.6 \%$ physicians considered that remuneration should not be given to HCP to report ADR. Responses of positive attitude are summarized in Table III.

Table III : Evaluation of Attitude of Physicians regarding ADR reporting

$\begin{array}{llr}\text { Serial No } & \text { Attitude } & \text { Physicians \% (Positive attitude) } \\ \text { 1. } & \text { Do you think that ADR reporting contributes to drug as well as patient safety? } & 90 \%(63) \\ \text { 2. } & \text { ADR reporting is a professional obligation/necessary. } & 80 \%(56) \\ \text { 3. } & \text { Do you feel that ADR reporting is time consuming activity with no outcome? } & 71.4 \%(50) \\ \text { 4. } & \text { Do you worry about legal problems while you think of ADR reporting? } & 42.9 \%(30) \\ 5 . & \text { Do you think ADRs reporting will waste your time. } & 90 \%(63) \\ 6 . & \text { Do you think that reporting of only 1 ADR makes no significant contribution to the } & 78.6 \%(55) \\ & \text { ADR reporting scheme? } & 81.4 \%(57) \\ \text { 7. } & \text { Pharmaceutical industries should also report ADRs } & 87.1 \%(61) \\ 8 . & \text { PV should be included in the official curriculum of all HCP } & 98.6 \%(69) \\ 9 . & \text { ADR monitoring/reporting should be done routinely for better patient care } & 8.6 \%(6) \\ 10 . & \text { Remuneration should not be given to the HCP to report ADRs } & 95.7 \%(67) \\ 11 . & \text { ADR reporting should be mandatory in a developing countries like Bangladesh } & 91.4 \%(64) \\ 12 . & \text { HCP can make the Pharmacovigilance successful in Bangladesh } & 98.6 \%(69) \\ 13 . & \text { Department of drug administration should take steps for strengthening PV in Bangladesh } & 92.9 \%(65) \\ 14 . & \text { Pharmacovigilance should be known in detail to all healthcare professionals? }\end{array}$


$58.6 \%$ physicians accepted that there were no practice of ADR reporting in their hospital and $41.4 \%$ physicians were not aware of whether it was practiced or not. No physicians admitted that reporting practice in their hospital is done. No of experienced ADR cases are described in Table 4. Among the physicians who were experienced of ADR in last 1 year, $81.35 \%$ experienced ADR with antibiotic, $33.89 \%$ with NSAIDs and $15.25 \%$ had experienced with antiepileptic. Among the physicians who experienced ADR with antibiotic, $41.66 \%$ experienced with Ceftriaxone, 25\% experienced with Ciprofloxacin. Physicians who experienced ADR, majority (44.06\%) experienced ADR with skin and $30.50 \%$ faced ADR with GIT and $22.03 \%$ faced ADR with respiratory system involvement (Table IV).

Table IV : Evaluation of Practice of Physicians regarding ADR reporting

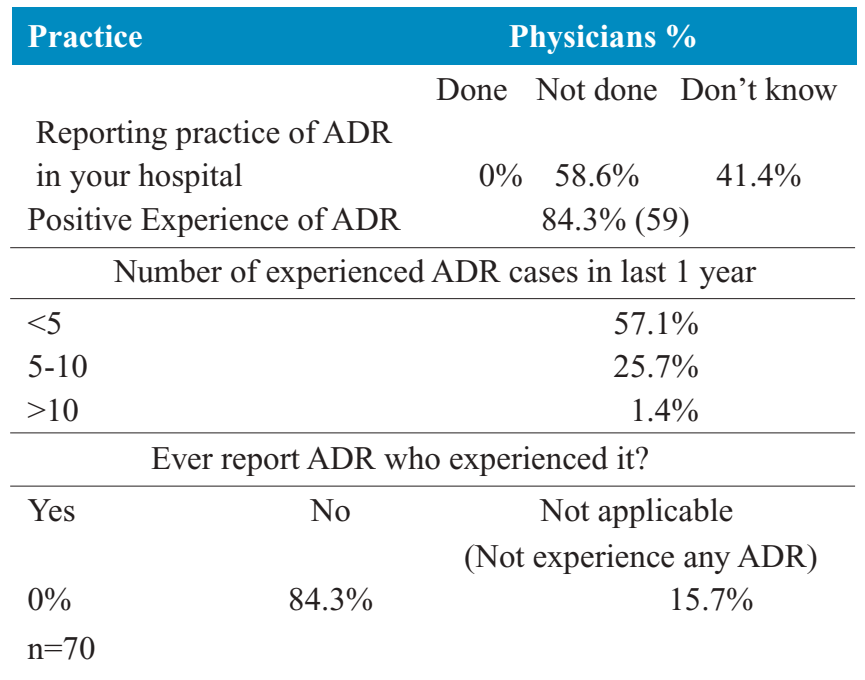

Professional reasons for not reporting ADR are listed in the Table V.

Table V : Opinion about barriers to ADR reporting

\begin{tabular}{lr} 
Barriers & Physicians (\%) \\
Reporting doesn't influence treatment scheme & $52.9 \%(37)$ \\
Busy schedule & $85.7 \%(60)$ \\
Lack of incentives & $71.4 \%(50)$ \\
I am not responsible for reporting as I didn't prescribe it. & $32.9 \%(23)$ \\
Don't know whom to report & $81.4 \%(57)$ \\
Waste of time & $21.4 \%(15)$ \\
Insufficient clinical knowledge & $57.1 \%(40)$ \\
Thinking one report doesn't make any difference & $55.7 \%(39)$ \\
Difficult to point out suspected drug & $74.3 \%(52)$ \\
Reporting forms are not available & $88.6 \%(62)$ \\
Fear of legal liability & $60 \%(42)$ \\
Don't know how to report & $85.7 \%(60)$ \\
Lack of confidence to be sure whether it is an ADR or not & $67.1 \%(47)$ \\
It generate extra work & $68.6 \%(48)$ \\
The reporting form was not clear & $74.3 \%(52)$ \\
Concern that report may be wrong & $68.6 \%(48)$ \\
Not motivated to report & $80 \%(56)$ \\
\hline n=70
\end{tabular}

Majority of physicians (97.1\%) opined that available and simpler reporting form encourage reporting. $85.7 \%$ physicians believed that regular provision of guideline and bulletins on ADR reporting impel them to report.

$48.6 \%$ physicians prefer mobile app for reporting and $48.3 \%$ physicians prefer online reporting submission which is available in our country.

\section{DISCUSSION}

The present study was cross sectional questionnaire based study in which the sample was Physicians of a tertiary medical college hospital. In this current study the response rate was $70 \%$ which is similar to that reported in other study like in Oman $(72.3 \%)^{15}$. Knowledge regarding ADR reporting is very important for physicians. The result showed that majority $(61.43 \%)$ of the physicians had adequate knowledge (Knowledge score $>66 \%$ ) related to ADR reporting which is in correspondence with studies conducted in Karachi Pakistan and Western Odisha India ${ }^{16,17}$. Knowledge regarding ADR reporting is very important for physicians. In this study $71.4 \%$ physicians knew the term Pharmacovigilance which was more and less similar to other study in Bangladesh ${ }^{18}$. Present study revealed $58.6 \%$ physicians were aware of existence of ADR monitoring centre in Bangladesh whereas $78 \%$ of the physicians were aware of ADR monitoring centre in West Bengal India ${ }^{19}$. In this study, majority of the physicians $(82.9 \%)$ had the knowledge that not only physicians but any health care professionals (HCP) and consumers should also have the rights to report which is mentioned in other studies too ${ }^{20,21}$. Majority of the physicians $78.6 \%$ and $90 \%$ had knowledge that OTC medication are not safe also and all the drugs in the market are not safe respectively which is similar to study done in Madhya Pradesh (MP) India $80 \%$ physicians in this study believed that ADR reporting is a professional obligation and this attitude is more or less similar to studies in India ${ }^{19,22}$. Majority (78.6\%) of physicians disagreed that reporting of only one ADR would not make any significant contribution to ADR database which was similar to study in India ${ }^{22}$. The study observed the positive attitude towards pharmacovigilance and ADR reporting.

Most of the physicians (84.3\%) experienced ADR in last one year which is similar to other study done in Kuwait ${ }^{23}$. It was very doleful that no physicians who experienced ADR in last one year had ever reported ADR to Adverse Drug Reaction Monitoring Cell (ADRMC) in Bangladesh. Actually there is no reporting practice done in last 1 year in this institution. Poor reporting practice had also been observed in other study in Ethiopia ${ }^{24}$. Most of the physicians faced ADR with antibiotic $(81.35 \%)$ NSAIDs (33.89\%) and anticonvulsant (15.25\%) and $44.06 \%$ physicians faced ADR were with skin, 30.50\% with GIT and $22.03 \%$ physicians faced ADR with respiratory system involvement which more or less corresponds with other study $^{25}$. 
Regardless of adequate knowledge and positive attitude, it was very disappointing that there is no reporting practice of ADR in this study. The most common reasons for underreporting were unavailability of reporting form, busy schedule (Lethargy) unawareness of how to report and whom to report, which in line with the other study ${ }^{26,27}$. All those reasons indicated that physicians are unaware of reporting form and their submission procedure which are available under national ADRMC of Bangladesh at DGDA website. Most of the physicians preferred mobile app (48.6\%) and online submission form (48.3\%) for reporting ADR. In our country online submission form are available in the website of DGDA which is unknown to our physicians as majority stated where and how to report is the reason behind underreporting.

Majority of physicians stated that there should be a simpler and available reporting form and regular guideline and bulletins on ADR reporting which might encourage them to report. This again reflects unawareness of physicians that online submission form is available in the website of DGDA.

\section{LIMITATIONS}

This study was done in one hospital setting and sampe size was not large enough due to pandemic situation of COVID 19.

\section{CONCLUSION}

Our study strongly suggests that there is an unmet need to create practice of ADR reporting. In spite of having fair knowledge and positive attitude; there is actually no practice of ADR reporting probably because of lack of awareness, lack of knowledge about our reporting form, and lack of reminder as a regular duty of doctors to report ADR, lack of training especially from intern period about the pharmacovigilance. CME, seminar, workshops, training program are also required for the same purpose. Successful implementation of spontaneous ADR reporting can be attained by making ADR reporting practice an indispensible part of clinical activities.

\section{ACKNOWLEDGEMENT}

The authors thank to all the participants for their support to make this study a successful one.

\section{DISCLOSURE}

All the authors declared no competing interest. 


\section{REFERENCES}

1. Lee A, Thomas SHL. Adverse drug reactions. In: Walker R and Edward C. Clinical pharmacy and Therapeutics. 3rd ed. Churchill Livingstone. $2003 ; 33-46$.

2. Ahmad A, Patel I, Sudeepa S, Balkrishnan R, Mohanta GP. A Study on Drug Safety Monitoring Program in India. Indian J Pharm Sci. 2014;76(5):379-386

3. Kohn LT, Corrigan JM, Donaldson MS. To err is Human: Building a Safer Health System. Institute of Medicine: Washington DC. 2000.

4. Tandon VR, Khajuria V, Mahajan A, Gillani Z, Mahajan V, Chandail V. Fatal adverse drug reactions: Experience of adverse drug reactions in a tertiary care teaching hospital of North India - a case series. Indian J Critical Care Medicine. 2014;18(5):315-319.

5. Swamy S, Bhanuprakash NP, Muralimohan SM. Profile of suspected adverse drug reaction in teaching tertiary care hospital. J Pharmacol Clin Toxicol. 2013;1:1005.

6. Sivadasan S, Yuong YN, Woan CN, Siew CA, Nazeri AA, Ravichandran V, et al. Knowledge and perception towards pharmacovigilance and adverse drug reaction reporting among medicine and pharmacy students. World J Pharm Pharm Sci. 2014;3(3):1652-1676.

7. World Health Organization. Safety of medicines: A guide to detecting and reporting adverse drug reactions.Geneva. 2002.WHO/EDM/QSM/2002.2

8. Canto MT. Public Health in the 21st Century. 2010. Praeger.

9. Nisa ZU, Zafar A, Sher F. Assessment of knowledge, attitude and practice of adverse drug reaction reporting among healthcare professionals in secondary and tertiary hospitals in the capital of Pakistan. 2018;26:453-461.

10. Lexchin J. Is there a role for spontaneous reporting of adverse drug reactions? CMAJ 2006;174:191-192.

11. Lopez-Gonzalez E, Herdeiro MT, Figueiras A: Determinants of under-reporting of adverse drug reactions: A systematic review. Drug Saf. 2009;32:19-31.

12. Smith $\mathrm{CC}$ et al. Adverse drug reaction in a hospital general medical unit meriting notification to the Committee on Safety of Medicines. Br $\mathrm{J}$ Clin Pharmacol. 1996;42:423-429.

13. Santosh KC, Tragulpiankit P, Gorsanan S, Edwards IR. Attitude among health care Professionals to the reporting of adverse drug reactions in Nepal. BMC Pharmacology and Toxicology. 2013;14 (16)

14. Khan MW. Pharmacovigilance system in Bangladesh: A Regulatory Perspective.EDWISER INTERNATIONAL. 2019;3(1).

15. Jose J, Jimmy B, Al Ghailani AS, Al Majali MA. A cross sectional pilot study on assessing the knowledge, attitude and behavior of community pharmacists to adverse drug reaction related aspects in the Sultanate of Oman. Saudi Phar J. 2014;22(2):163-169.

16. Iffat W, Shakeel S, Rahim N, Anjum F, Nesav S, Ghayas S. Pakistani physicians knowledge \& attitude towards reporting adverse drug reactions. Afr J Pharm Pharmacol. 2014; 8(14):379-383.

17. Saha $\mathrm{S}$, Rath B, Agrawal R. survey of knowledge, attitude and practice of adverse drug reaction monitoring among doctors in Western Odisha region. IJBCP. 2018;7(11):2234-2239.

18. Hossain MA, Amran MS. A Cross-Sectional Pilot Study on Pharmacovigilance to Improve the Drug Safety in Bangladesh. Biomedical and Pharmacology journal. 2019. 12(3):

19. Adhikari A et al. Knowledge, attitude and perception of physicians towards adverse drug reaction (ADR) reporting: a pharmacovigilance study. International Journal of Advances in Medicine. 2017;4 (6): 1685-1689.

20. van Grootheest AC, van Puijenbroek EP, de Jong-van den Berg LTW. Contribution of pharmacists to the reporting of adverse drug reactions. Pharmacoepidemiol Drug Saf. 2002;11:205-211.

21. de Langen J, van Hunsel F, Passier A, de Jong-van den Berg L, van Grootheest K, authors. Adverse drug reaction reporting by patients in the Netherlands. Three years of experience. Drug Saf. 2008;31:515-524.

22. Khan SA, Goyal C, Chandel N, Rafi M. Knowledge, attitudes, and practice of doctors to adverse drug reaction reporting in a teaching hospital in India: An observational study. J Nat Sci Biol Med. 2013;4(1):191-196.

23. Alsaleh FM, Lemay J, Al Dhafeeri RR, AlAjmi S c, Abahussain EA a, Bayoud T. Adverse drug reaction reporting among physicians working in private and government hospitals in Kuwait.Saudi Pharmaceutical Journal. 2017; 25:1184-1193.

24. Nadew SS, Michael Beyene KG, Beza SW. Adverse drug reaction reporting practice and associated factors among medical doctors in government hospitals in Addis Ababa, Ethiopia. PLoS ONE. 2020; 15(1):1-19.

25. Mishra R, Jeevangi SK, Vardhamane S, Kumar S. Pharmacovigilance study in medicine department in a tertiary care hospital. International Journal of Basic \& Clinical Pharmacology. 2016;5(6):2608-2615.

26. Lemay J, Alsaleh FM, Al-Buresli L, Al-Mutairi M, Abahussain EA, Bayoud T. Reporting of Adverse Drug Reactions in Primary Care Settings in Kuwait: A Comparative Study of Physicians and Pharmacists. Medical Principle and Practice. 2018. doi: $10.1159 / 000487236$

27. Amin MN, Khan TM, Dewan SMR, Islam MS, Moghal MR, MingLC. Cross-sectional study exploring barriers to adverse drug reactions reporting in community pharmacy settings in Dhaka, Bangladesh. BMJ Open. 2016; 6(8): e010912. doi:10.1136/bmjopen-2015-010912. 